\title{
Practical quality monitoring of bituminous binders used at federal highways construction
}

\author{
Sergey Chernov, Evgeny Eremenko*, and Nikita Shiryaev \\ Don State Technical University, 344000 Rostov-on-Don, Russia
}

\begin{abstract}
The work is devoted to the applied bitumen binders' quality practical monitoring results at construction sites, repair and reconstruction of highways in the Russian Federation at all the production and technological stages, from their manufacture by the supplier, including transportation and storage, and ending with their use in the production of asphalt concrete mixtures. The quality control of bituminous binders was carried out according to the modern methods of Russia and abroad
\end{abstract}

\section{Introduction}

Highways and engineering equipment on them are an important component of the transport ecosystem in the Russian Federation. The economic situation of the state is directly related to the transport system efficiency. The road transport structure is one of the main tools in solving major geopolitical and economic problems. [1] Assessing today the state of the transport system cannot be considered optimal, and the level of its development is sufficient. Today's volumetric and qualitative characteristics of the road infrastructure do not allow to fully and effectively solve the problems of the growing economy. The development of the road network and the maintenance of a high level of transport and operational indicators of highways, ensuring comfortable and safe movement of vehicles, are the main tasks of the road industry.

It should be noted that the quality of materials used for the construction, repair and maintenance of highways is the most important component of the road surface durability. One of the main structural components of asphalt concrete mixtures are organic binders bitumen, polymer-bitumen binders and polymer-modified bitumen. The quality of these materials is directly related to the resistance of asphalt concrete to the destructive factors during operation. [2] For the production of organic binders in our country, a fairly wide range of petroleum feedstocks are used, using different technologies for the production of an organic binder. Sometimes the situations when incompatible components are used in the preparation of polymer-modified organic binders arise, which leads to the heterogeneity of the final product properties, and often is the reason for the deterioration of its quality indicators, both during transportation and during storage. Recently, the use of polymermodified bitumen in advanced industrial countries has become more and more widespread.

\footnotetext{
* Corresponding author: eremenkoeugene@gmail.com
} 


\section{Main part}

About $35 \%$ of all organic binders used in road construction are modified with various polymers, but mainly within styrene-butadiene-styrene groups. [3] The increase in the use of polymers is due to the desire to ensure the operational stability of road surfaces in conditions of increasing traffic intensity and increasing axle load of vehicles. A number of studies have shown that the modification of bitumen with polymers contributes to an increase in the shear and rut resistance of asphalt concrete, as well as their resistance to fatigue failure. [4] Along with this, international studies of asphalt concrete based on modified binders show that traditional methods of assessing the quality of polymer-bitumen binders and asphalt concrete based on them do not allow to fully judge the performance of coatings made using these materials.

In this regard, an urgent task is to monitor the quality of binders at all production and technological stages, from their manufacture by the supplier, including transportation and storage, and ending with their use in the production of asphalt concrete mixtures [5].

Having identified certain types of binders that most effectively manifest themselves during the road structure operation, it will be possible to conduct a comparative analysis of the qualitative characteristics of modifying additives, polymer-bitumen binders and asphalt concrete based on them.

As a part of the work on monitoring the quality of organic binders used by the specialists of Don State Technical University, a visit to the places of production of binders was made in order to take samples in the required amount in accordance with the normative and technical documentation regulating the volume of samples and the list of tests performed. The work was carried out according to three sets of tests for compliance with the requirements of the regulatory and technical documentation of the Russian Federation, taking into account a number of innovative property indicators characterizing the rheological state of binders at real operating temperatures. In order to monitor the quality and stability of the properties of the studied binder samples, samples of the same batch were also taken from the bitumen truck delivering the binder to the place of work, and from the working tank of asphalt concrete mixing plant. [6] After drawing up the "act of sampling", all samples were transferred to the laboratory №3 IC "Akademstroytestaniya" for the purpose of identifying the compliance of physical and chemical and physical and mechanical indicators of binders' samples with the requirements of regulatory documents, and a comparative analysis of the qualitative characteristics of binders depending on the selection place.

The main producers of viscous road oil bitumen used at major repairs, reconstruction and construction projects of the State Company Avtodor [7] were «JSC Gazpromneft», Ltd. «Lukoil-Volgogradneftepererabotka», construction bitumen 60/90 production «Salsk bitumen terminal», Ltd. «KINEFF» and Ltd. «PH-Bitumen». By manufacturers ORP and PBB were Ltd. «Bitumix», Ltd. «Road technologies», LTD. «Gazpromneft-BM», LTD. «TNB Victoria», LTD. «Joint company «Autobahn», Ltd. «Petrochim technologies», Ltd. «NDST», JSC «CMO-Dondorstroy», Ltd. «Trans Real», Ltd. «Asphalt concrete mixing plant Leninsky».

During the monitoring period, a total of 216 samples of viscous oil road bitumen, 360 samples of polymer-bitumen binders and polymer-modified bitumen and 36 samples of improved oil road bitumen were taken. 


\section{CONSTRUCTION BITUMEN \\ $60 / 90$ according to GOST 22245 - \\ 90 it is possible to classify as}

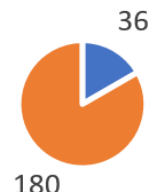

- construction bitumen 50/70

- construction bitumen $70 / 100$
Sample conformity according

to GOST 33133-2014

144

- meets the requirements

$\approx$ does $\cdot$ not $\cdot$ meet $\cdot$ the $\cdot$ requirements

All samples of viscous oil road bitumen were tested for compliance with the requirements of GOST 22245-90 and GOST 33133-2014. The main brand according to GOST 22245-90 was construction bitumen 60/90, [9] however, when testing these binders for compliance with the requirements of GOST 33133, according to the depth of penetration of the needle at $25^{\circ} \mathrm{C}$ two brands stood out: construction bitumen 50/70 (36 samples) and construction bitumen 70/100 (180 samples).

In total, all samples of viscous oil road bitumen met the requirements of GOST 22245-90 to the grade construction bitumen $60 / 90$, but at the same time 144 samples, which is $67 \%$ of the total sample volume, did not meet the requirements of GOST 33133 in at least one indicator.

The main indicators of physical and chemical properties, according to which bitumen does not meet the requirements of GOST 33133 are:

- softening temperature (for bitumen grade construction bitumen 50/70)

- extensibility at $0^{\circ} \mathrm{C}$ (for bitumen grade construction bitumen 70/100)

The main problem of viscous road oil bitumen produced in accordance with GOST 22245-90 is their poor resistance to high temperatures. Almost all tested samples did not meet the requirements and exceeded the permissible values for the "change in softening point". It is also worth noting that after aging using the RTFOT method, the dynamic viscosity increased more than 4 times, which indicates intensive aging processes, which can lead to a decrease in the service life of the asphalt concrete road structural layer with the use of these binders.

The tests analysis showed a change in the parameters "depth of the needle penetration at $25^{\circ} \mathrm{C} \gg$ from $6 \%$ to $17 \%$ of the initial, the difference in the indicators "depth of the needle penetration at $25^{\circ} \mathrm{C} »$ and "dynamic viscosity" in the samples taken at different technological stages indicates aging processes taking place due to prolonged exposure to temperature. A decrease in the "softening point" of bitumen taken from a working boiler can occur due to the introduction of an adhesive additive.

All tested samples of improved oil road bitumen met the requirements OST AVTODOR 2.1-2011. No significant discrepancies from the sampling site were found during testing.

During the period of monitoring the quality of organic binders, the quality of polymermodified bitumen was assessed by 9 manufacturers.

All samples of polymer-bitumen binders and polymer-modified bitumen were tested for compliance with the requirements of GOST R 52056-2003, OST Avtodor 2.30-2016, as well as the standards of organizations agreed with SC Avtodor. At the objects of major repairs, reconstruction and construction of highways $Г K$ Avtodor. The main brands of polymermodified bitumen for OST Avtodor 2.30-2016, ORP 50/70 and ORP 70/100 were prepared 
with the use of a polymer type styrene-butadiene-styrene modifier. Polymer-modified bitumen with the use of thermoplastic polymers was not used during the monitoring period.

In the process of monitoring the polymer-modified bitumen quality for the entire reporting period, 87 samples did not meet the requirements of the regulatory and technical documentation for at least one indicator, which is $24 \%$ of the total volume of the studied samples, and 11 samples did not meet the requirements for 3 or more property indicators.

Polymer-modified bitumen that did not meet the RTFOT aging resistance requirements accounted for $10.3 \%$ of all tested samples. The main discrepancy is revealed when determining the following indicators:

- weight change after heating;

- change in softening temperature after heating;

- elasticity after heating;

- residual penetration after heating.

It should be noted that ORP three manufacturers repeatedly did not meet the requirements for stability during long-term storage. Total number of non-compliant samples of standards and technical documentation according to the indicators "Change in softening temperature after heating within 72 hours" and "Change in penetration after heating within 72 hours" was 24 , which is $7 \%$ of the total volume. Poor storage stability could be due to the fact that manufacturers did not use binding agents, and also used industrial oils and their components as a plasticizer [9].

However, to a greater extent, the correspondence of the main indicators of the polymermodified bitumen physical and mechanical properties indicates a long-term preservation of their homogeneity during transportation, storage and use, and minor changes identified during the analysis indirectly indicate the nature of organic binders [11], and their inherent tendency to age under prolonged exposure to temperature.

The set of tests also included additional indicators of rheological properties determined after "technological" aging by the method RTFOT and PAV service aging such as "complex shear modulus on a dynamic shear rheometer (DSR)", "low temperature stiffness on a bend rheometer (BBR)" and "low temperature creep on a bend rheometer (BBR)".

\section{Conclusion}

Due to the fact that on the territory of the Russian Federation, a program to introduce organic binders into road construction according to the SuperPave methodology is being implemented. Rationing and mandatory determination of the polymer-modified bitumen rheological properties will make it possible to be classified according to $\mathrm{PG}$, taking into account the grades GOST R 58400.1 or GOST R 58400.2.

This monitoring highlighted promising areas for acceptance control of bitumen binders used at construction sites. In connection with the use of various component composition by production enterprises for specific bituminous binders, there was a lack of stability "within the brand" of the properties for various physical and chemical parameters. [12] These measures made it possible to identify "unscrupulous" suppliers whose products do not correspond to a number of properties that directly characterize the quality of bituminous binders and are able to predict the service life of asphalt concrete pavements.

\section{References}

1. S.A. Chernov, N.N. Konoplev, Stability assessment of the properties of organic binders used in road construction, In the collection: CONSTRUCTION AND 
ARCHITECTURE-2017. ROAD TRANSPORTATION FACULTY (Materials of the scientific and practical conference Academy of Civil Engineering and Architecture) (2017)

2. I.V. Mardirosova, A.V. Kaklyugin, S.A. Chernov, A.A. Khudokonenko, Improving the road building materials' quality through modification with polymer additives (In the book: SCIENTIFIC TECHNOLOGIES AND INNOVATIONS International Scientific and Practical Conference) (2016)

3. S.A. Chernov, A.V. Kaklyugin, E.V. Lekontsev, I.V. Mardirosova, Science and technology in the road industry 3 (77) 20-23 (2016)

4. S.A. Chernov, E.A. Eremenko, N.A. Protsenko, M.E. Mandrykina, Roads and bridges 2 (34) 21 (2015)

5. A. Vasiliev, I. Stefanenko, V. Azarov, D. Nikolenko, The study of the aerodynamic characteristics of dust particles in the air of roadside areas (International Conference on Modern Trends in Manufacturing Technologies and Equipment, ICMTMTE 2019) Sevastopol, Russia (2019)

6. OST Avtodor 2.30-2016. Polymer-modified bitumen. Technical conditions. (official publication)

7. E.V. Uglova, E.A. Eremenko, N.V. Sikacheva, K.A. Kuzin, Transport structures 1 (2019) https://t-s.today/PDF/04SATS119.pdf, DOI:10.15862/04SATS119

8. S.K. Iliopolov, E.A., Eremenko, I.V. Mardirosova, Construction and reconstruction 1 (45), 69-75 (2013)

9. Superpave Performance Graded Asphalt Binder Specification and Testing (Series 1 (SP1) Asphalt Institute Superpave, 1997)

10. T.S. Khudyakova, World of roads, 68-76 (2014)

11. G. Mironov, Complex work of JSC "Gazprom Neft" to improve the quality of bituminous materials and the development of technologies for their application, 10- 12 (2013)

12. Yu.I. Kalgin, Scientific Bulletin of VSACU, Series: Road transport construction 1, 47 $51(2003)$ 